\title{
Senior Scientist Award
}

National Cancer Institute

\section{Source}

National Cancer Institute. Senior Scientist Award. NCI Thesaurus. Code C20034.

The Senior Scientist Award (K05) provides stability of support to outstanding scientists who have demonstrated a sustained, high level of productivity and whose expertise, research accomplishments, and contributions to the field have been and will continue to be critical to the mission of the particular NIH center or institute. The award provides salary support for award periods of five years as a means of enhancing the individual recipient's skills and dedication to his/her area of research. 